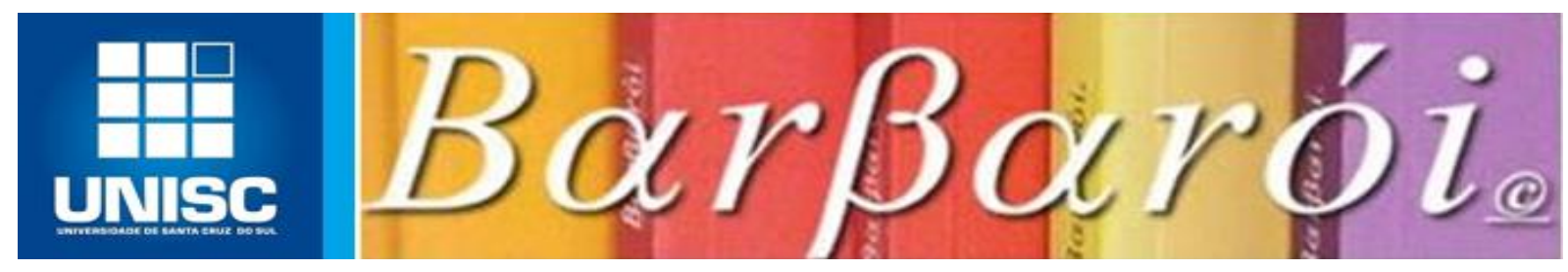

\title{
¿RESULTA POSIBLE QUE UN PUEBLO SE AUTOGOBIERNE? UNA PARADOJA GENERADA POR LA AMBIGÜEDAD ENTRE PARTICIPACIÓN Y REPRESENTACIÓN EN LA LIBERTAD DE LOS MODERNOS EN EL CONTEXTO DE LA LIBERTAD DE LOS ANTIGUOS
}

\author{
DOI: http://dx.doi.org/10.17058/barbaroi.v0i0.5239 \\ José Agustín Millán Muñoz \\ Universidad Simón Bolívar - USB - Venezuela
}

\section{Resumen:}

El propósito de este texto es exponer una relación sociológica obviada por muchos analistas políticos en la actualidad entre el concepto de pueblo, la crisis de representación del cuerpo de lo político que de aquel concepto se deriva y la ambigüedad que se patentiza con las crisis entre participación y representación de la libertad de los modernos en el contexto de la libertad de los antiguos. De esta manera, queremos realizar una comprensión sociológica sobre esa relación relegada, desplegando sobre ella una pregunta, la cual es concerniente de la posibilidad de que un pueblo se autogobierne y las consecuencias de anulación y destrucción de los ejercicios de deberes y derechos que toda ciudadanía democrática reporta, y el pasmo que esto supone con el concepto de habitante, como base de todo ciudadano, permitiendo la construcción ideológica y utópica de una ficción de un pueblo soberano. En definitiva: una ralentización, parálisis y anulación de la ciudadanía moderna.

Palabras Claves: Pueblo. Participación. Representación. Libertad antigua y moderna.

\section{Introducción}

Desde que Benjamín Constant expresó con su texto clásico expuesto desde el Ateneo de París en 1819 que lleva como título: De la libertad de los antiguos comparada con la libertad de los modernos, siempre me ha llamado la atención, el siguiente pasaje, si lo apreciamos en el contexto vivido políticamente por Venezuela desde 1999:

En primer lugar, la confusión de estas dos clases de libertad ha causado muchos males entre nosotros, en el transcurso de algunas etapas tristemente célebres de nuestra revolución. Francia se ha visto importunada con experimentos inútiles, cuyos autores, irritados por su escaso éxito, la obligaban a disfrutar de los bienes que no deseaba, y le regateaban los que ella quería.

En segundo lugar, llamados por nuestra feliz revolución, (la llamo feliz a pesar de sus excesos porque me fijo sólo en sus resultados) a disfrutar de las ventajas del gobierno representativo, resulta útil e interesante averiguar por qué este tipo de gobierno, el único que puede proporcionarnos hoy cierta libertad y tranquilidad, fue prácticamente desconocido entre las naciones libres de la Antigüedad

(..)En Roma, los tributos tenían hasta cierto punto una misión de representación. Eran los órganos de aquellos plebeyos que la oligarquía (que en todos los siglos es la misma, cursivas mías) había sometido a tan dura esclavitud, al derrocar a los reyes. Sin embargo, el pueblo ejercía directamente gran parte de los derechos políticos. Se reunía en asamblea para votar las leyes, para juzgar a los patricios acusados de algo. En Roma no había, pues, más que débiles vestigios de un sistema representativo (Constant, 2000: 1) 
Resulta relevante de grado sumo que esa ausencia en la libertad de los antiguos y su necesaria presencia con la libertad de los modernos, pudiera constituir una paradoja, especialmente, en sistemas políticos democráticos como el que evidencia el caso venezolano a fines del siglo XX y comienzos del siglo XXI, el cual ha nacido de procesos constituyentes, los poderes del estado, y con ello no se logre distinguirse entre los ciudadanos, el denominador común existente al relacionar por parte de ellos, la participación y la representación, mediante elecciones, fusionándolos como iguales, dado así los diferentes niveles de cargos de elección popular, creando de esa forma, una paradoja que encierra la promesa de posibilidad de que el pueblo se autogobierne mediante procesos constituyentes, garantizando procesos electorales de carácter procedimental mediante el ejercicio de participación ciudadana.

Esa ausencia presencial pero a la vez ausente que genera esta formulación de la paradoja por parte del elector, la va a realizar desde, una retrospectiva que le hace valorar la libertad de los antiguos, a saber: la presencia en ausencia que los llevará a pensar, incluso, a plantearse como factibilidad del ser social, pero jamás plantarse en defensa de sus derechos y deberes como ciudadanos ante las autoridades que ellos han elegido, porque se le ha postulado la idea de que el q pueblo puede auto gobernarse, desde sí y para sí, para utilizar términos de raigambre hegeliana-sartreana y que se garantiza ello por procedimientos electorales recurrentes mediante participación mas no por representación.

Visto de este modo, resulta determinante en la formulación de la ambigüedad, el delegar mas no el representar, en el acto mismo del ejercicio del voto por parte ciudadano, puesto que al delegar el elector de ese modo privilegia cierta concepción de la igualdad ciudadana mediante la participación, la cual le permite establecer y seguir reglas de procedimientos electorales, donde por ese mecanismo, se expresa y se dará consistencia a cuerpos políticos, en términos de agregados sociales, que poseerán carácter difuso y al mismo tiempo que confuso, que se manifestará como voluntad popular del soberano, el cual se va a privilegiar el ejercicio de autogobierno, idea que ha sido promovida por parte de proyectos políticos de carácter ideológico y/o utópicos, mediante procedimientos constituyentes; canalizando de ese modo en un líder carismático y su organización política portadora de esos sus proyectos, uno de los puntos centrales de toda democracia: la mayoría, pero debilitando, al mismo tiempo, la expresión de respeto legal y legitimo de la minoría comporta en un sistema democrático moderno, repotenciando, de este modo, la omnipotencia de la mayoría, tal como lo conceptualizo Alexis de Tocqueville, en su clásica obra La Democracia en América, (Tocqueville, 1973:256), viéndola como fuente inestable pero 
legitimador del ejercicio delegado del poder soberano, en términos de legislatura, inestabilidad que se subraya con el contexto de un proceso de constituyente de poderes del Estado nuevos, más allá de los tres tradicionales que evidencia el sistema político venezolano desde 1999 hasta nuestros días.

Todo esto si bien se permite el que se renuevan periódicamente, incluso con referenda, las deliberaciones del soberano popular mediante mecanismos de participación popular: se paga, sin embargo, un precio muy alto respecto de la presencia de una perspectiva de sistema democrático de carácter representativo, a saber:

a-. La liquidación del disenso de las minorías siempre reportan.

b-. La anulación de libertades privadas que es el síntoma de que ese agregado social llamado pueblo termina avalando proyectos políticos hegemónicos y personalistas, a decir de Carl Schmitt,comisariales, (Schmitt, 2003: 28), que, si bien pueden concitar una mayoría para mandatos, sean ejecutivos o legislativos, cooptan y cercenan lo que Constant ha llamado Libertad de los Modernos, ofreciendo con la idea de que pueblo se autogobierna, ya reducción inducida a la libertad de los antiguos..

De ahí, pues, el propio Constant señale esto, al distinguir ambas libertades, la necesidad de un sistema representativo de gobierno que se desprende perentoriamente de las características esenciales de la libertad moderna, más no de la antigua, (Constant , 2000: 6):

\footnotetext{
No es a la libertad política a la que quiero renunciar, es la libertad civil la que reclamo, junto con las otras formas de libertad política. Los gobiernos no tienen ahora más que antes el derecho de arrogarse un poder legítimo. Pero los gobiernos no proceden de una fuente legítima tienen menos aún que antes el derecho a ejercer una supremacía arbitraria sobre los individuos. Poseemos todavía hoy los derechos que siempre tuvimos, esos derechos eternos a consentir en las leyes, a deliberar sobre nuestros intereses, a ser parte integrante del cuerpo social del que somos miembros. Pero los gobiernos tienen nuevos deberes. Los progresos de la civilización, los cambios operados por los sigilos, imponen a la autoridad más respeto por las costumbres, por los afectos, por la independencia de los individuos. Debe tocar estas cuestiones con mano aún más prudente y ligera.
}

No obstante, existe una ambivalencia que está contenida en el principio de igualdad moderna, que no sólo hace que ese proceso sea imposible sino que también posibilita procesos de ideologización y/ utopizacion, creadores de paradojas entre los ciudadanos de una nación, especialmente en procesos constituyentes en el marco de crisis del sistema político democrático, como el caso de Venezuela desde 1999.

Estos procesos de ideologización y/ utopizacion han podido y pueden rentar desde el principio de representación moderna, una reducción conducente a la libertad de los antiguos desde la anulación del ejercicio de la libertad de los modernos generando así la ambigüedad entre participación y representación en los ciudadanos votantes en procesos constituyentes de 
sistemas políticos en crisis, como evidencia el caso de Venezuela desde 1999, el cual da pie a la posibilidad de que un pueblo se autogobierno pero permitiendo, a los legisladores o gobiernos involucrados en estos procesos, sustituir un gobierno representativo mediantes apelaciones carismáticas de liderazgo o de rutinización del mismo por intermedio de constituciones refrendadas por asambleas constituyentes; para así hacer mayorías democráticas mediante participación, mas no por representación, legitimando y factibilizando el que se dé la impresión de que se gobierne como gestor al servicio del pueblo, pero siendo todos esto, actos procesos de enajenación social ampliamente reductoras del comportamiento institucional de carácter universal que todo proceso social de organización contiene.

El propio Constant lo evidencia de este modo (2000: 7):

\begin{abstract}
Esta reserva de la autoridad que es su estricto deber, cosa que una organización que ayuda a una nación a descargar en algunos individuos lo que no puede o no quiere hacer por sí misma. Los pobres realizan ellos mismos sus asuntos. Los ricos tienen intendentes. Es la historia de las antiguas naciones y de las modernas. El sistema representativo es un poder otorgado a determinado número de personas por la masa del pueblo, que quiere que sus intereses sean defendidos y que sin embargo no tiene tiempo de defenderlos por sí mismo Pero, a menos que sean insensatos, los ricos que tienen intendentes vigilan con atención y severidad si dichos intendentes cumplen con su deber, si no son descuidados, corruptos, incapaces: y para juzgar la gestión de esos mandatarios, los mandadores prudentes se enteran bien de los asuntos, cuya administración confían. De igual manera los pueblos que, con objeto de disfrutar de la libertad que les corresponde, recurren al sistema representativo, deben ejercer una vigilancia activa y constante sobre sus representantes, y reservarse, en periodos que no estén separados por intervalos demasiado largos, el derecho de apartarles si se han equivocado y de revocarles los poderes de los que hayan abusado.
\end{abstract}

Con el presente texto, deseo explorar esa imposibilidad que el pueblo se autogobierne desde los parámetros de la relación entre participar y representar, que, al confundirse perceptivamente en los individuos, al no discernir el denominador común a ellas, es decir la presencia, se permite reducirle a la categoría de miembro del pueblo al ciudadano elector y que esa reducción conducente, que avala la imposibilidad de que un pueblo se autogobierne, legitima la ruptura entre los derechos y deberes que todo cuerpo representado tiene como servicio para con el cuerpo de electores que lo elige, haciendo, de esta forma palmaria, una paradoja que encierra la ambigüedad que resulta de equiparar participación y representación mediante procedimientos y reglas electorales como Poder del Estado tal ha sido el caso de Venezuela desde 1999 con su ultima constitución política.

De igual manera es, también, relevante, el analizar la pregunta que acá nos hacemos en el contexto de la ambigüedad que produce la igualdad moderna en la cultura política de una sociedad moderna, pues ella misma produce la paradoja que, según consideramos, anula un elemento clave de la soberanía popular en las democracias modernas, el cual es la legitimidad 
de un gobierno representativo, proveniente del ejercicio individual del ciudadano, trayendo como consecuencias, problemas de rechazo, banalización y trivialización del poder ciudadano, socavando así lo propiamente legítimo que esa representatividad del gobierno genera a favor de mayorías de la voluntad popular y con el respeto a las minorías en una democracia moderna.

En este sentido, hemos querido dividir este texto en dos partes y una conclusión. La primera expondremos los puntos concernientes a la relación entre participar y representar, cuya ambigüedad proveniente de la ambivalencia con que se observa modernamente el principio de igualdad moderna.

Si bien podemos declarar con la imposibilidad del autogobierno del pueblo, esta idea da pie a que se mine la legitimidad del gobierno representativo, con lo cual al declarar su imposibilidad, resulta perentorio establecer una mejor comprensión funcionamiento del sistema de gobierno representativo para superar esa imposibilidad de un autogobierno del pueblo.

De este modo con la idea de que un pueblo se autogobierne, no se le hace justicia a la distinción que bien observó Benjamín Constant, entre la libertad de los antiguos y la de los modernos, reduciendo y pervirtiendo así el poder legitimo del poder representativo de gobierno elegido en elecciones democráticas hacia formas retrospectivas de la libertad de los antiguos que si bien pudieran tener carácter legal ciertamente manifiestan dudosas formas de legitimación, altamente perjudiciales para el ejercicio de la ciudadanía democrática moderna.

Con la segunda parte, mostraremos cómo la ambivalencia del principio de igualdad moderna, permite esa reducción con ideologizar y/o utopizar lo que bien distinguió Constant con las libertades antiguas y modernas; y de qué manera, estas reducciones requieren del instrumento de la historia, de una "narrativa interesada" de los acontecimientos de la historia de una sociedad, para así anular, al menos perceptivamente, la distinción entre libertad de los antiguos y la de los modernos entre los miembros de una sociedad por la misma vía electoral y obtener legitimidad de procedimiento democrático para tal reducción de la libertad moderna a la antigua, usando de esta forma la ambigüedad entre participar y representar, posibilitando la idea de que el pueblo de autogobierne.

Por último, estableceremos las conclusiones que estas reflexiones nos reportan, en el contexto de lo que implica la perspectiva del sistema político venezolano de estos últimos 18 años. 


\section{Primera parte. Distinción entre participar y representar. Su Importancia. Surgimiento} de la categoría de pueblo y su forma "política" de autogobierno.

\section{1-. En qué consiste la distinción entre participar y representar.}

Esta distinción es posible tanto fáctica y lógicamente, porque hay individuos, y por tanto relación. Con este elemento posibilitador, podemos distinguir aquel elemento que tiende a confundir a ambos términos en una identidad y que es un denominador común en ambos, a saber, la presencia.

En este sentido, podemos decir con un autor, Rafael Alvira, en su texto participación y representación: Una encrucijada metafísico-política, señala lo siguiente:

\footnotetext{
Participar y representar no son lo mismo y, sin embargo, las vemos como actividades cercanas, tanto en sí mismas como en su encarnación política.

La cercanía entre una y otra se fundamenta en que ambas se refieren de forma marcada a la realidad de la presencia. El que participa hace presente la realidad de lo participado y también el que representa hace lo mismo. ¿En qué se distingue, pues, lo uno de lo otro?

A primera vista se nos muestra la participación como una forma más íntima de presencializar que la mera representación, y por eso, parecer ser primaria. Puede que en un cierto sentido lo sea, pero, en un primer momento, ello no aparece suficientemente claro. (Alvira, 2003:17-18)
}

En otras palabras, la diferencia está en el nivel con que la presencia relaciona aquello que es distinto, por ende, podemos distinguir dos formas de presencia a saber:

A-. Presencia individualizante. Es aquella que refiere lo que está ausente, no sólo lo respeta, sino que puede conocerla al representársela mediante una mediación, y, por tanto puede informarla comunicativamente a los demás; formulando desde las formas esenciales del lenguaje que nos permite reconocernos como miembros de una sociedad siendo distintos entre nosotros mismos, como las formas más genuinas del conocer científico, pasando por el filosófico.

Puede, por tanto, representar, representarse a sí mismo y reflexionar mediatamente, gracias a eso por qué está ausente, que la presencia mediadora característica de todo representar.

b-. Presencia existencial. Es aquella que se atiene a aspectos esencialmente incomunicables e íntimos del individuo como miembros de su sociedad, es decir, sus aspectos de vida privada e íntima que sólo concernientes a él y aquellos que él considera que pudieran compartir esos elementos, sí y sólo así, logra identificar a esos aspectos incomunicables con su pensar, sentir y concebir y los expresa como presencia inmediata.

Por consiguiente, la presencia del representar genera mediación que hace justicia a la individualización y su relación concibe matices, formas de reconocimientos factibles en 
diversidad. En cambio, la presencia existencial, es inmediata, es disyuntiva, es todo o nada, solo conoce si es posible convertirla a formas inmediatas de sentir, pensar y concebir.

\title{
1.2-. La ambigüedad de la igualdad moderna como razón para identificar participación y representación.
}

La ambigüedad de la igualdad moderna, proviene de qué se puede identificar lógicamente, emancipación, con libertad individual y atribuirlo a un pueblo que postule la posibilidad de que es loable mediante participación directa, protagónica y refrendario, autogobernarse como colectivo indivisible y único, pues, la igualdad no acontece en el tiempo y la libertad es una facultad que es inherente a la persona humana. Es un atributo que hace justicia a la inmediatez de tu condición más íntima y más privada de tu existencia.

Esto ha hecho que se obvie y se reconozca por parte del individuo, el tiempo, lugar y circunstancia de procesos complejos que políticamente dan forma y contenido a la organización moderna de los individuos.

Por este motivo, Alvira señala, claramente, esta ambigüedad cuando escribe en un pasaje de su ya mencionado texto lo siguiente:

\begin{abstract}
Los grupos humanos, las personas diversas, se agrupan en unidades y esa unidad tiene siempre una cierta forma comprensible- una idealidad-, aunque nunca pueda estar completamente explícita y pide unas personas- los gobernantes- que se encarguen "energéticamente" de mantener y perfeccionar esa unidad. No hay unidad sin forma, ni forma sin alguien que se haga cargo de "gestionarla" activamente.

Para gobernar una "polis" hace falta como base primera comprender su forma y dedicar tiempo a su atención. El ideal de la igualdad pediría que todos conocieran la forma y tuvieran tiempo, por un lado, de un lado entonces el ideal se autodestruiría, pues carece de sentido que todos gobiernen al tiempo, y, de otro, completamente unido al anterior, ¿Quién se dedicaría a las tareas necesarias para la vida y para cuyo gobierno último se requiere precisamente a esas personas? (Alvira, 2003: 24-25).
\end{abstract}

La ambigüedad que reporta el principio de igualdad moderna, radica entonces, que al no reconocerse la importancia de la presencia del individuo, se tendería a confundir participación y representación, posibilitando tanto, lógica, como fácticamente, mecanismos colectivos de reducción de la conducta del comportamiento del vínculo social, anulando la distinción que postulara Constant, imposibilitando que el vinculo social que nace con la presencia del individuo, se creara un gobierno representativo.

Entendido esto, se nos aclara que no sólo resulta imposible que un pueblo de autogobierne, sino que constituye un discurso ideológico con característica altamente utópica, 
el que se ofrezca, a nombre de la igualdad moderna, la posibilidad de reducir la categoría de ciudadanos, a la ciudadanía como nacionalidad y ésta a la categoría pueblo.

En este sentido, es bien interesante lo que Beneton en un texto suyo titulado Acerca de la participación democrática, la versión sana y la versión corrompida, diga de esta ambiguiedad lo siguiente:

Los hombres son, por tanto, políticamente iguales. ¿A título de qué? Según la igualdad por defecto, la igualdad de los ciudadanos resulta de la igualdad de opiniones, y la igualdad de opiniones resulta ella misma de la ausencia de la verdad. A cada uno su "libertad", nadie puede aspirar a la Verdad en sí, el pluralismo es una virtud en sí mismo. Por consiguiente, el ciudadano no se halla investido de la dignidad propia, de una misión elevada; posee su papeleta de voto por las mismas razones que justifican la autonomía del individuo, razones esencialmente negativas.

En términos substanciales, la igualdad política responde a todas las demás razones. La igualdad de los ciudadanos no es más que una convención, pero es la convención más acorde con la igualdad primaria entre los hombres y la dignidad de cada ser humano. El principio democrático marca el final de un tiempo en el que el nacimiento distinguía a los hombres, da un voto a los modestos, a los oscuros, a los sin grado, limita las pretensiones de los Importantes, la prepotencia de los Magníficos. Los hombres en el poder tienden a considerarse gente de otra especie y a mirar desde muy arriba a los hombres ordinarios. La igualdad democrática (siempre en su versión substancial) contrarresta esta tendencia natural, encarna una similitud esencial que prima sobre todas las grandezas, particularmente las grandezas de lo establecido. Correlativamente reconoce en cada uno la calidad de ser racional, capaz de elegir y de procurar los intereses comunes; haciendo esto adquiere su virtud fundamental, le confiere honor a cada uno y en primer lugar a los pequeños (2003: 31).

Al no poderse discernir, tanto cognoscitivamente como volitivamente por parte de los miembros de una sociedad, lo que se reporta con la presencia inmediata en los miembros de una sociedad, se echan las bases para que con esta ambigüedad que postula la igualdad moderna, sean seductoramente embaucados tales miembros, por ideologías-utopías que hacen sobrestimar una de las igualdades, la de defecto, en contra de la substancial: posibilitando la idea de que resulta posible que el ciudadano enajene sus poderes inherentes como persona humana, y se quiera convertir en miembro del pueblo, al querer participar en una categoría como la del pueblo, pensando que con esta pertenencia "participativa y protagónica" pudiera darle existencia inmediata a un autogobierno del pueblo, para el pueblo y por el pueblo, como esencialmente democrático, "protagónico y participativo".

\section{Segunda parte. De qué manera la ambigüedad de la igualdad moderna hace ideológico y utópico la idea de un pueblo que se autogobierne.}

\subsection{Como reduce la conducta individual la igualdad por defecto.}

Uno de los aspectos esenciales de la presencia que comporta y reporta el individuo como factor discerniente respecto a la ambigüedad que promociona la igualdad moderna es 
que al estar unida con la idea de libertad negativa como forma de emancipación de los seres humanos, no resulta posible el poder entender la realidad política que significa su vínculos con los demás ciudadanos, al menos en dos dimensiones:

1-.El ser humano por su condición de ser, es único e irrepetible, por más procedimiento de colectivización y homogeneización social haya, siempre percibirá la realidad como ningún otro a él y pudiera expresarlo de manera distinta y clara, por más idéntico que le pudiera sugerir un colectivo respecto a otros seres humanos.

2-. Que el carácter de expresividad, en la condición de igualdad es necesaria mas no suficiente pues tiende a privilegiar privaciones en vez de reconocimiento, haciéndole sentir, pensar y percibir con ello que con su opinión, por más similar que sea a la de otro, nace de su condición de ser íntimo, de sus privaciones, de sus ámbitos privados, haciendo de sus ausencias, presencias de su existir inmediato, pues, la expresividad que él tiene que realizar ante, por y frente a los demás es similar a la del vecino, de sus compañeros, de sus colegas, de sus congéneres.

En el punto 1-. podemos hacer una expresividad representativa al hacerle justicia al carácter individual que todo ser humano tiene y que interpreta claramente en sus expresiones comunicacionales respecto a sí mismo y los demás.

Desde esa expresividad representativa, se puede ir más allá de las opiniones y hacer posible y factible, una libertad de expresión genuina, con base a la difusión de información mediante el proceso de comunicación desde los distintos ámbitos con que este se manifiesta en una sociedad moderna.

De esta forma el individuo y los que él puede agrupar y expresar desde sus condiciones de desempeño de estatus y de rol y los que pudiera no estar en sus líneas de horizonte, tiene el poder d convivir y mejorar los procesos de la dinámica social que el vinculo social que como individuo r comporta y tienen en él un garante fundamental.

Con el punto 2, obtenemos la posibilidad que no sólo no se supere la ambigüedad que postula la igualdad moderna, sino que se pierda la condición de ciudadano, por incitarle a una participación "democrática y "protagónica", desde su existencia misma como presencia, la cual, por definición, es siempre privada e intima, (libertad negativa), y que al decir de Alvira, resulta incomunicable (Alvira 2003:19).

Con esa "participación", se consiste una preservación de las libertad negativas como miembros del pueblo, incitándoles, desde ahí, a un "festival de opiniones", donde vale todo, y que resulta imposible trascender, pues, todos somos deseos, ausencias y privaciones, donde los discursos políticos que tienen la forma mercantil de conjugación del negocio de lo íntimo 
con lo privado, pueden, de esta manera, rentar y postular la idea que los ciudadanos pertenecen al pueblo que requieren de un hacedor, de un demiurgo que les posibilite sus formas de convivencias, mientras ellos se dedican a quedarse en las existencias que sus ámbitos privados e íntimo, característica esencialmente propia de la libertad de los modernos, como lo expresó Constant.

Esto que bien temió Alexis de Tocqueville con sus magníficos análisis en la Democracia en América (1982: 37), lo podemos sintetizar con un pasaje relevante de un texto de Marcelo Imperiale, denominado, Individualismo y democracia:

\begin{abstract}
Si en aras de la "igualdad" acentuamos la anulación de toda diferencia, corremos el riesgo de invalidar aún aquellas que representan la riqueza personal de cada individuo, tomándolas como peligrosas y excluyentes, Nos referimos a aquellas diferencias naturales, aptitudinales, con cuyo desarrollo cabal y conveniente cada individuo puede, solidariamente, brindar su aporte a la sociedad, participando en la cosa pública. Esta "diferenciación" entre los ciudadanos, no tiene por qué ser necesariamente "clasista"; no proviene ni de la herencia, ni de la mayor o menor riqueza; no es fruto del poder o de la fuerza; antes bien, repugna a este tipo de fundamentos, pues surge de "algo" natural de cada uno; no supone, de suyo, la ruptura del entramado social, sino que bien puede enriquecerlo con matices siempre nuevos, abriendo genuinas "posibilidades de progreso.
\end{abstract}

La anulación de toda diferencia, además, concita en los espíritus la idea de independencia absoluta. ( $\mathrm{Si}$, en suma, el "otro" no tiene "nada" distinto a mí, nada que me pueda aportar y nada puedo ni debo esperar de él. Mi suerte está librada en mis manos). La independencia absoluta conduce al egoísmo. Privada la sociedad de esta suerte de "desigualdad natural", corre el riesgo de quedar reducida a mera agrupación de individuos aislados, sin vínculos que doten de sentido al asociarse mismo y que, por consecuencia, quite interés en la participación por los asuntos públicos. El poder democrático erigido sobre esta plataforma, es el poder del número, de la mayoría...

Eso es lo que, para nosotros, constituye la categoría de pueblo: un mero agregado social de egoístas que se quedan meramente en sus libertades negativas y que así desvanecen o imposibilitan vínculos sociales al no devenir personas sino en destacarse como individuos.

Con el mecanismo ilusorio de un auto gobierno del pueblo, avalado por meros procedimientos electorales que convienen a la igualdad por defecto (Beneton, 2003 : 33), elevan a "sagradas", las reglas y los procedimientos electorales de una democracia moderna, haciéndonos creer que con eso, hay más y mejor democracia; y lo que terminan es legitimando, por esos medios, formas anti democráticas de desarrollo e involución de la ciudadanía, avalando así las astucias afortunadas del "Príncipe" de turno, dada las circunstancias históricas.

\title{
Conclusiones
}

La afirmación central que se desprende de este texto, en relación a nuestra pregunta que lo ha originado, es simplemente una afirmación: es imposible que el pueblo se 
autogobierne, y, además, postularlo sería no sólo un engaño, sino una "estafa", pues, al ser imposible, lógicamente, uno se puede hacer otra pregunta a raíz de esa imposibilidad: ¿Es posible que haya discurso que reconozca realidades y lógicas? ¿Cómo lo hace?

La respuesta no es sólo un no rotundo, sino que deja una factibilidad que siquiera admite una disyuntiva incluyente, pero si excluyente, como ya vio Maquiavelo en su capítulo 9 de El Príncipe(2003), elemento éste sumamente importante para valorar, estimar y dar cuenta con discursos, ejecuciones, comunicaciones e informaciones de "astucia afortunada", el que por, con y del pueblo, se quieren hacerse pasar como genuinos desarrollos "democráticos" para, con y desde los miembros de "este" o "aquel" pueblo, se pudiera desarrollar sistemas políticos con estas retrospectivas respectivas, como ha quedado en evidencia con el sistema político venezolano desde 1999 .

Con esa factibilidad, esa posibilidad se registra como realidad, gracias a un discurso ideológico y/o utópico que, en términos de relación entre individuo y sociedad, niegue como agente de cambio social, al individuo portador de presencia representativa tan vital para la libertad de los modernos en términos de representación.

Desde esa negación, se da pie a la presencia de la categoría de pueblo como "legitima" porque el mismo por su participación como expresión existencial de su libertad negativa, pudiera concebir la idea de que como pueblo se autogobierna, la cual se origina de la disyuntiva excluyente, a saber, si un pueblo se autogobierna, sólo es posible y factible mediante un discurso de su líder, de su príncipe, el cual mediante una forma de transferencia ideológica y utópica (forma de astucia afortunada), puede transferir el poder constituyente de ese agregado social, a un colectivo elite o individuos que administre su conducta diversa y plural en realidad única del pueblo soberano, en formas de manejo de lo añejo de lo que le ha constituido como historia y tradición, impidiendo el surgir del individuo como forma civilizatoria de lo moderno.

Con esta posibilidad, se puede apreciar esta categoría de pueblo como forma autogobernada, proporcionando de esa manera, la existencia de esa categoría como presencia inmediata de la libertad negativa de los miembros constituyentes del pueblo, y otorgar, de una manera administrada, contrato social, a los conglomerados egoístas e indiferenciados que surgen de una sociedad moderna, una sociedad de egoístas con libertad negativa, los cuales, se regulan, según las formas del contrato social moderno, presentándosele la factibilidad de administrar el "uno para todos y todos para uno", que proporciona el masificar a cualquier acto del individuo, desde su actividad y opinión como los miembros de una sociedad de masas, pero ya no tanto como individuos, sino como meros existentes, en la defensa de su 
legítimo gobernante, con lo cual su participación avala "legítimamente" cualquier discurso que les haga " justicia".

Esa "justicia" no sólo es ficticia sino aduladora, seductora y reductora como lo muestra un inquietante y revelador texto de Carl Schmitt, llamado "La Dictadura", cuando en un pasaje, nos indica :

\footnotetext{
...En el marco de una explicación científico jurídica; la distinción entre dictadura comisarial y dictadura soberana. Tal distinción constituye, teóricamente, la transición de la primitiva dictadura de la "Reforma" a la dictadura de la Revolución, sobre la base del pouvoir constituant (poder constituyente) del pueblo. En el siglo XVIII, aparece por primera vez en la historia de Occidente cristiano, un concepto de dictadura, según el cual el dictador permanece en realidad comisario, pero que, a consecuencia de la peculiaridad no del poder constituido, sino del poder constituyente del pueblo es un comisario inmediato del pueblo, un dictador que dicta incluso a su comitente, sin dejar de legitimarse en el ( $2003: 29$
}

Con nuestra pregunta, queremos dejar claro, que eso es sólo una posibilidad que debe ser denunciada, por discernientes formas de percepción individual de análisis fáctico de realidades, donde al declarársele como un imposible, nos proporciona factibilidades de desarrollo, evoluciones y discernimientos de parte del individuo que es, por definición, lógica y empíricamente, el agente genuino y propio de un desarrollo factual de perspectivas de sistemas políticos que se dan, no sólo en nuestras mentes sino en realidades, puntos éstos, que muestra la eficiencia y "bondades" del mismo más allá de la lógica y de las reducciones que ciertos discursos ideológicos-utópicos pudieran realizar, como lo muestra el caso venezolano y el sistema político que surgió de la constitución de 1999 y que durante 18 años ha estado vigente.

Esto es lo que hay que tener en cuenta, dado lo complejo y las dificultades que reporta la concepción de la dinámica político social de una sociedad moderna y que todo analista de sistema político tiene a bien considerar como de importancia para la estimación lo más certera posible de las realidades que para los profesionales que estudian como científicos el comportamiento humano y de sus instituciones.

\title{
IS IT POSSIBLE FOR A PEOPLE TO GOVERN THEMSELVES? A PARADOX GENERATED BY THE EQUALITY BETWEEN PARTICIPATION AND REPRESENTATION IN THE FREEDOM OF THE MODERNS IN THE CONTEXT OF THE FREEDOM OF THE ANCIENTS
}

\begin{abstract}
The purpose of this text is to expose, a sociological relationship obviated by many political analysts at present between the concept of the people, the crisis of representation of the body of the political that derives from that concept and the ambiguity that is evident with the crises between participation and representation of the freedom of the moderns, in the context of the freedom of the ancients. In this way, we want to make a sociological understanding about this
\end{abstract}


relationship, by displaying a question about the possibility of the people's self-government and the consequences of the annulment and destruction of the rights and rights exercises that all democratic citizenship reports and the shock that this implies in the concept of inhabitant, as the basis of this, allow the ideological and utopian construction of a fiction of a sovereign people: in short, slowdown, paralysis and cancellation of modern citizenship.

Keywords: People, Participation, Representation, Freedon ancient and modern.

\section{SERIA POSSÍVEL QUE UM POVO SE AUTOGOVERNE? UM PARADOXO GERADO PELA AMBIGÜIDADE ENTRE PARTICIPAÇÃO E REPRESENTAÇÃO DA LIBERDADE DOS MODELOS EM ÇONTEXTO COM A LIBERDADE DOS ANTIGOS}

\section{Resumo}

O propósito desse texto é expor uma relação socióloga observada por muitos analistas políticos na atualidade entre o conceito do povo, a crise de representação do corpo político de que aquele conceito se deriva e a ambigüidade se assemelha com a crise entre participação e representação da liberdade dos moldes no contexto da liberdade dos (antiguos). Dessa maneira queremos realizar uma compreensão socióloga sobre essa relação (relegada, al desplegar) sobre ela uma pergunta convincente a possibilidade de que um povo se autogoverne e as consequências de anulação e destruição dos exercícios e deveres e direitos que toda cidadania democrática denuncia e justamente isso que pressupõe que o conceito de habitante, como base de aquele permitindo a construção ideológica e utópica de uma ficção de um povo soberano: em definitiva (ralentización), paralisia e anulação da cidadania moderna.

Palavras Chaves: Povo, Participação, Representação, liberdade antiga e moderna

\section{Bibliografía}

Alvira, R. (2003). Participación y representación. Una encrucijada metafísico-política. Pamplona: Eunsa.

Beneton, P. (2003). Acerca de la participación democrática. La versión sana y la versión corrompida. Pamplona: Eunsa.

Constant, B. (2000). De la libertad de los antiguos comparada con la de los modernos. Madrid: Centro de Estudios Constitucionales.

Imperiale, M. (2004). Individualismo y democracia. Pamplona: Eunsa.

Maquiavelo, N. (2003). El príncipe. Madrid: Mestas Ediciones.

Tocqueville, A. (1973). La Democracia en América. México: F.C. E.

Schmitt, C. (2003). La Dictadura. Desde los comienzos del pensamiento moderno de la soberanía hasta la lucha de clases proletaria. Madrid: Alianza Editorial.

Data de recebimento: 30/09/2014

Data de aceite: $21 / 12 / 2017$

\section{Sobre o autor:}

José Agustín Millán Macsabio es licenciado de sociología de la universidad católica Andrés Bello de Caracas. Magister ciencia política en la Simón Bolívar. Endereço Eletrônico: josemillan@usb.ve 